\title{
Performance Enhancement of Spaceborne Cooler Passive Launch and On-Orbit Vibration Isolation System
}

\author{
Yeon-Hyeok Park, ${ }^{1}$ Mun-Shin Jo, ${ }^{2}$ Eung-Shik Lee, ${ }^{3}$ and Hyun-Ung Oh $\oplus^{1}$ \\ ${ }^{1}$ Space Technology Synthesis Laboratory, Department of Aerospace Engineering, Chosun University, Gwangju, Republic of Korea \\ ${ }^{2}$ Mechatronics Groups, Hanwha Systems, Republic of Korea \\ ${ }^{3}$ Satellite Payload Development Division, Korea Aerospace Research Institute, Republic of Korea
}

Correspondence should be addressed to Hyun-Ung Oh; ohu129@chosun.ac.kr

Received 9 November 2019; Revised 18 February 2020; Accepted 17 April 2020; Published 4 August 2020

Academic Editor: Antonio Viviani

Copyright (c) 2020 Yeon-Hyeok Park et al. This is an open access article distributed under the Creative Commons Attribution License, which permits unrestricted use, distribution, and reproduction in any medium, provided the original work is properly cited.

\begin{abstract}
A spaceborne cryogenic cooler induces undesirable microvibration disturbances during its on-orbit operation, which is one of the main sources that degrades the image quality of submeter-level high-resolution observation satellites. Several types of vibration isolation systems based on passive approaches have been developed for reducing the microvibration of the cooler. A coil-springtype passive vibration isolation system developed in a previous study has shown excellent performance in both launch vibration and on-orbit microvibration isolation. To improve the capability of the conventional cooler isolator, including the position sensitivity and launch vibration reduction, we propose a new version of a dual coil-spring-type passive vibration isolator system. The effectiveness of the newly proposed design was validated through a microjitter measurement test, position sensitivity test, and qualification-level launch vibration test of the isolator.
\end{abstract}

\section{Introduction}

Spaceborne pulse tube-type cryogenic coolers are widely used to cool the focal plane of an infrared imaging sensor, because of advantages such as low cost, a simple mechanism, high reliability, low mechanical vibration, and an electronic noise comparison with the traditional Stirling-type cooler [1-3]. However, these coolers also generate undesirable microvibrations during on-orbit operation, which may seriously affect the performance of microvibration-sensitive payloads of high-resolution observation satellites, even though the vibration level is much lower than that of the Stirling-type cooler. Therefore, to obtain high-quality images from submeter-level high-resolution observation satellites, microvibration isolation of the cooler is an important task for advanced space missions [4].

To meet the strict microvibration requirement for highresolution observation satellites, mounting an isolator is a solution, as this attenuates the transmitted microvibration to the microvibration sensitive payload. Passive vibration isolation systems, which are attractive vibration isolation methods, have the advantages of simplicity, robustness, and reliability [5-12]. Several types of passive vibration isolation systems were proposed in previous studies. Richard et al. [5] proposed a hexagonal-type isolator with low-stiffness to support the spaceborne cooler. The validity of this system was verified through vibration isolation experiments, and the results indicated that the system exhibits $20 \mathrm{~dB}$ of isolation performance for the cooler harmonic disturbances. Ellis et al. [6] proposed a commercial wire rope vibration isolator to support a cube satellite miniature cryocooler system. The commercial wire-rope isolator in the existing hardware can be easily implemented without significant modifications to the cooler, while effectively isolating the cryocooler-induced microvibration. Riabzev et al. [7] proposed a multidimensional passive vibration isolator including a triple-stage spring mass system mounted on an oscillating cold tip of the cooler, which has low stiffness characteristics in the lateral direction of the coil spring. The effectiveness of this isolation system was investigated by incorporating an analytical model and performing an experiment. Veprik et al. [8] proposed a vibration protection system for infrared applications 
employing a K527 split-Stirling linear cryogenic cooler manufactured by the RICOR company. This system consists of a stiffened and heavily damped vibration isolator with a tuned dynamic absorber using an Oxford-type flexural element to suppress the self-induced force by a large factor of 20 times at the driving frequency of the cooler. Kamesh et al. [9] proposed various flexible passive isolators of various thicknesses and bending struts for the microvibration isolation of disturbance sources including the cryogenic cooler, by decoupling between the excitation frequency of the cooler and the natural frequency of the entire isolation system. John et al. [10] proposed a dual-stage passive vibration isolation system (VIS) for the cryocooler of the ASTRO-H satellite. This proposed system consists of a launch vibration isolator using a cast viscoelastic bumper housing and an on-orbit isolator with a metallic flexure, to provide broadband jitter reduction during on-orbit operation and vibration load attenuation during launch. The researchers verified the effectiveness of the design through numerical and experimental approaches. Veprik et al. [11] proposed a single tuned dynamic absorber (TDA) and low-frequency vibration mount to suppress microvibration at the driving frequency of the Stirling-type cryocooler. The combination of a TDA and low-frequency vibration mount allows for effective attenuation of microvibration at the fundamental frequency and provides for the essential isolation of its multiples. This system exhibits 490 ratio of the suppression performance at the driving frequency of the cooler. Kwon et al. [12] proposed a pseudoelastic SMA blade-type isolator that satisfied the desirable jitter isolation performance regardless of the $0 \mathrm{~g}$ or $1 \mathrm{~g}$ condition. The proposed isolator can guarantee structural safety of the cooler assembly under harsh launch vibration conditions, without additional launch lock system, and effectively isolating the microvibration of the cooler in on-orbit environments. The position sensitivity test results indicated that the isolator can guarantee stable jitter isolation performance regardless of $1 \mathrm{~g}$ effects. Takuma and Sakai [13] proposed a passive type flux-pinned microvibration isolator for cryocooler. The flux pinning effect can maintain the relative distance and attitude between a cooled type-II superconductor and a permanent magnet passively as a result of the pinning force. The characteristic of the proposed isolator such as the damping and spring coefficient is analyzed using the numerical calculation model. Yang et al. [14] proposed a passive vibration isolation system for space optical payload in orbit. This isolator consists of double-deck leaf spring with in-filling silicon rubber. This design can reduce the stress on the leaf type springs and increase the damping characteristic, making it suitable for the vibration attenuation of sensitive instruments. The effectiveness of the isolator is validated by the dynamic model, FEA (finite element analysis), and experimental test. The test shows that the proposed analysis approach is valid, and moreover, this isolator can efficiently attenuate spaceborne disturbances. Burkie et al. [15] proposed a microsat cryocooler system with a thermal strap which is connecting the compressor to the radiator plate. The reason for using the thermal strap rather than securing the compressor rigidly to a plate is to allow for movement. Isolation through flexures from the compressor to the radiator plate further expands flexibility for movement, allowing the mitigation of vibrations escaping from the passive balancer of the cooler. Robinson et al. [16] proposed a soft mount vibration isolation system using the metallic flexure and viscoelastic damping material for TIRS cooler. The frequency of the flexures was tuned such that the rigid body mode of the cooler mount on the flexures were between $9 \mathrm{~Hz}$ and $30 \mathrm{~Hz}$. This system shows the vibration isolation performance by a factor of 10 . Kwon et al. [17] proposed a multilayered blade isolator with a double-sided adhesive tape to attenuate the microjitter induced by a spaceborne cryogenic cooler. This isolator indicated that stable jitter reduction performance could be obtained owing to the unsusceptible alignment sensitivity of the isolator. Moreover, the effectiveness of the isolator design without an additional launch-lock device was demonstrated through a qualificationlevel launch vibration test.

The validity of the proposed system was verified through vibration isolation experiments, and the results indicated that the system exhibits $20 \mathrm{~dB}$ of isolation performance for the cooler harmonic disturbances. With regard to the passive isolator, the microvibrations of the cryocooler can be isolated by using an isolator with low stiffness, which decouples the main operation frequency of the cooler and the natural frequency of the cooler assembly supported by the isolator. However, the structural safety of the cooler supported by an isolator with a low stiffness to achieve better isolation performance, cannot be endured under the launch environment. This problem can be solved easily if the cooler assembly supported by the low stiffness isolator is integrated with a hold and release mechanism during launch while being released at on-orbit. However, this has the disadvantages of system complexity and an increase in the total mass. Moreover, if the hold and release mechanism fails to release the mechanical constraint of the isolation system on-orbit, then the isolator cannot ensure isolation performance and is directly involved in the performance degradation of the optical system. To overcome the aforementioned disadvantages, Oh et al. [18] proposed a passive launch and onorbit vibration isolation system (PLOVIS) with space heritage through the KOMPSAT-3A program [19]. PLOVIS can effectively attenuate microvibrations of the cryogenic cooler under both launch and on-orbit vibration environments, without an additional hold and release mechanism. PLOVIS achieved effective cooler microvibration isolation by utilizing three coil springs with relatively low stiffness in the lateral direction. However, position sensitivity test results indicated that the normalized transmitted force ratio between $0 \mathrm{~g}$ and $1 \mathrm{~g}$ was 4.52 . This means that the performance of the isolator is sensitive to the aligned nominal position of the isolator which guarantees the isolation performance. However, the position sensitivity of the conventional PLOVIS was not measured in the previous study [18]. In addition, the vibration test results to verify the design effectiveness of PLOVIS at the qualification level of the launch vibration environment indicated that PLOVIS is not effective for the attenuation of sine vibration launch loads owing to insufficient damping of the coil springs, even if the maximum acceleration of the cooler does not exceed the design load of the cooler. 
In this paper, we propose a dual coil-spring-type passive vibration isolation system to improve the performance of the conventional PLOVIS in terms of its position sensitivity for microvibration isolation and the attenuation of launch vibration loads. The proposed isolator employs low-stiffness coilsprings to isolate the microjitter during on-orbit operation and relatively higher-stiffness coil-springs to attenuate the launch vibration loads. The main features of the proposed dual coil-spring-type passive vibration isolator are low sensitivity to the aligned position of the isolator and reduced launch vibration in comparison with the conventional PLOVIS. The effectiveness of the microjitter attenuation capability and the position sensitivity of the proposed isolator design were validated by performing a microvibration measurement test. In addition, to validate the effectiveness of the design in terms of the attenuation of launch loads, sine and random vibration tests were performed. These test results demonstrated that the newly designed isolator showed a much higher performance enhancement than the conventional PLOVIS from the viewpoints of position sensitivity and launch load attenuation.

\section{Necessity for Design Modification of Conventional PLOVIS}

Figure 1(a) shows the microvibration measurement test setup of the IR detector assembly, which consists of an image sensor and cooler (described as a compressor in the figure) integrated with PLOVIS on a KISTLER table to measure microvibration of the cooler. For microvibration isolation, the cooler is supported by four PLOVIS arranged in the center-of-gravity plane of the cooler. The details of the PLOVIS are shown in Figure 1(b), and the combination of three coil springs is useful to achieve a passive isolation system based on the frequency decoupling approach between the cooler excitation frequency and the natural frequency of the isolation system. In this method, a relatively lower stiffness in the lateral direction of the coil spring than axial direction is aligned to the main excitation axis of the cooler. The system showed remarkable isolation performance when the position of the cooler assembly was kept in the nominal position; in fact, this guarantees isolation performance. However, there is the possibility of inducing performance degradation when the cooler assembly is shifted out of the nominal position during unexpected misalignment and thermal distortion of the heat pipes additionally integrated in the cooler for heat transportation from the cooler. In practice, it is difficult to achieve the precise alignment of a cooler integrated with the transfer line and heat pipe at the nominal position of the isolator for obtaining the optimal isolation performance. Therefore, a considerably less position-sensitive isolation system is preferable to reduce the potential risk with regard to system reliability. Moreover, to satisfy stricter specifications of launch vibration test, it is necessary to enhance the vibration attenuation performance in severe launch environments in comparison with the conventional PLOVIS, whose damping on the coil-springs was insufficient. The main objective of this research is to enhance the performance of the conventional PLOVIS in terms of position sensitivity for the microvibration isolation and attenuation of launch vibration loads.

\section{Design Description of PLOVIS-II}

Figure 2(a) shows an exploded view of a dual coil-spring-type passive launch and on-orbit vibration isolator to improve the performance of the conventional PLOVIS. Front and isometric views of the integrated isolator are shown in Figure 2(b). In this paper, the new version of the cooler isolator is termed PLOVIS-II. The isolator comprises two-types of coil-springs with low- and high-stiffness values, a displacement limiter, moving plate, shaft cover, and support bracket. The lowstiffness coil-springs mechanically connect the support bracket and mechanical shaft cover. The mechanical shaft cover of the isolator is integrated into the mechanical shaft of the cooler, as shown in Figure 2(a). The nominal position of the isolator in orbit, as shown in the front view in Figure 2(b), is the main contributor to the microvibration isolation performance. This position, recovered by the restoration force of the extended or contracted coil springs under a launch environment, guarantees a relatively lower stiffness isolation system along the length direction of the cooler, which corresponds to the critical excitation axis of the cooler. This makes it possible to achieve sufficient frequency decoupling between the main excitation frequency of the cooler and the isolation system. In contrast, the high-stiffness coilsprings are mechanically connected between the moving plate and support bracket. The movement of the moving plate supported by coil-springs under a launch environment is limited to the in-plane direction, owing to the displacement limiter. By contrast, low-stiffness coil-springs move within the allowable deflection range of the spring in the translational and rotational directions along each axis. The axial stiffness value $(9.8 \mathrm{~N} / \mathrm{mm})$ of the high-stiffness coilspring was selected to support the cooler in the gravity direction in the $1 \mathrm{~g}$ condition. As a result, mechanical contact occurs only between the shaft cover and moving plate, and not at the displacement limiter, in the gravity direction under the $1 \mathrm{~g}$ condition. This design enables the attenuation of the transmitted microvibration level during cooler operation, in contrast to PLOVIS, where the shaft cover directly contacts the displacement limiter when the gravitational force due to the mass of the cooler presses the isolator under the $1 \mathrm{~g}$ condition.

For launch vibration reduction, the displacement limiter, moving plate, and shaft cover are made from the high-damping plastic material Delrin [20] with space heritages. The intention behind the design is to dissipate and mitigate launch vibration loads transmitted to the cooler when slip and contact occur between the plastic and plastic materials with high damping characteristics. In addition, the moving plates, combined with high-stiffness coil-springs, influence the attenuation of launch loads when the mechanical shaft cover bumps to the moving plates. This might be more effective than the conventional PLOVIS in reducing the launch loads transmitted to the cooler. The displacement limiter protects the transfer line of the cooler within the allowable deflection range of $\pm 2 \mathrm{~mm}$ during lateral and 


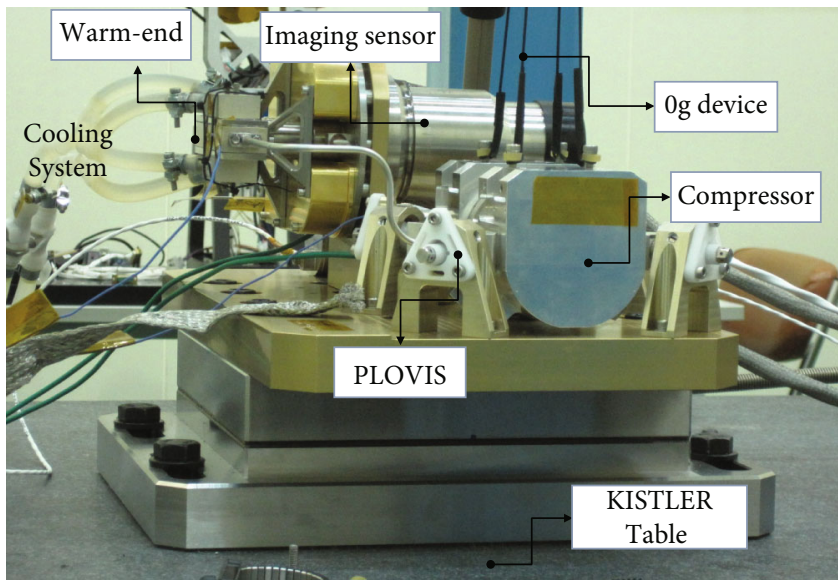

(a)

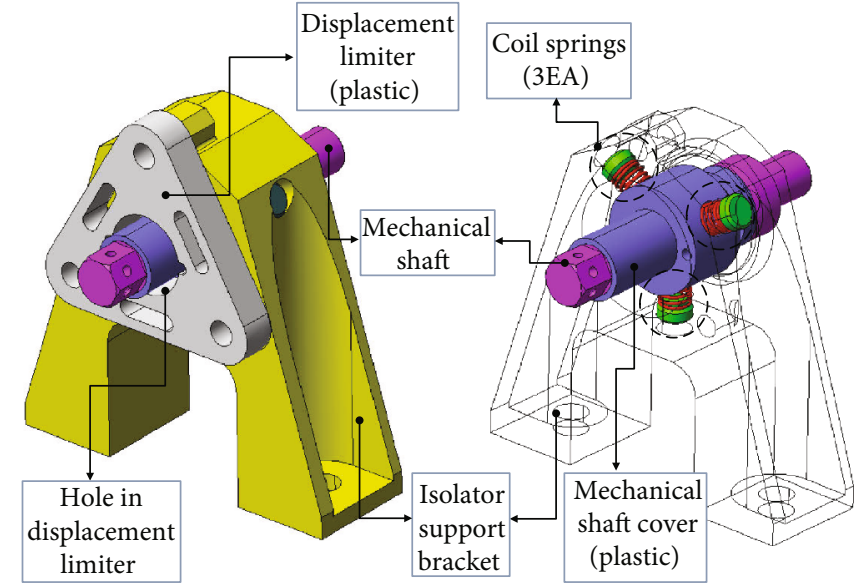

(b)

FIgure 1: Configuration of the conventional PLOVIS ((a) microvibration measurement test set-up of the compressor assembly integrated with PLOVIS, (b) isometric view of PLOVIS) [13].

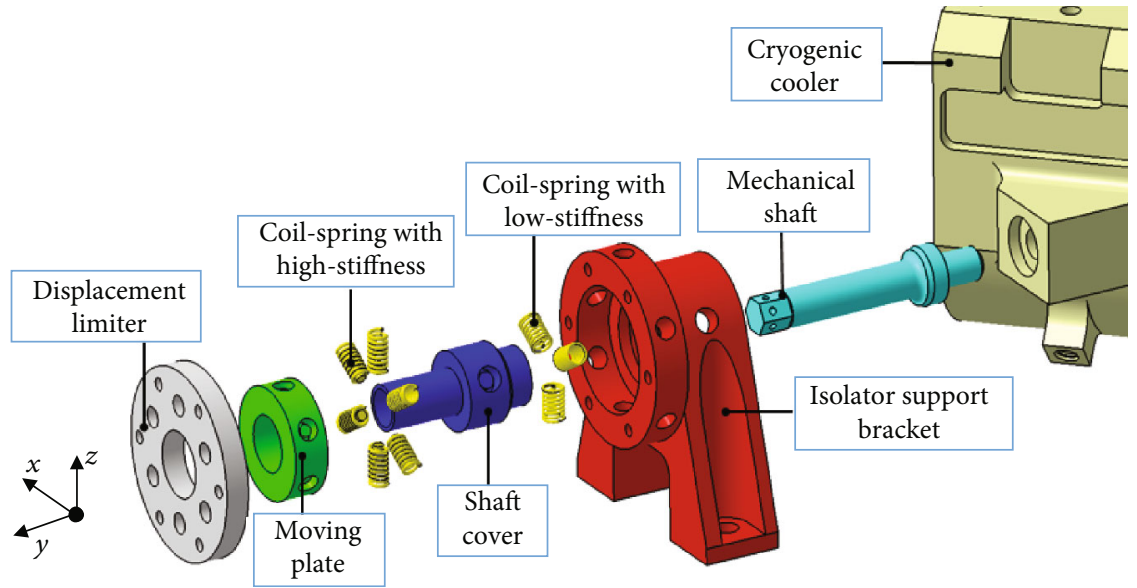

(a)
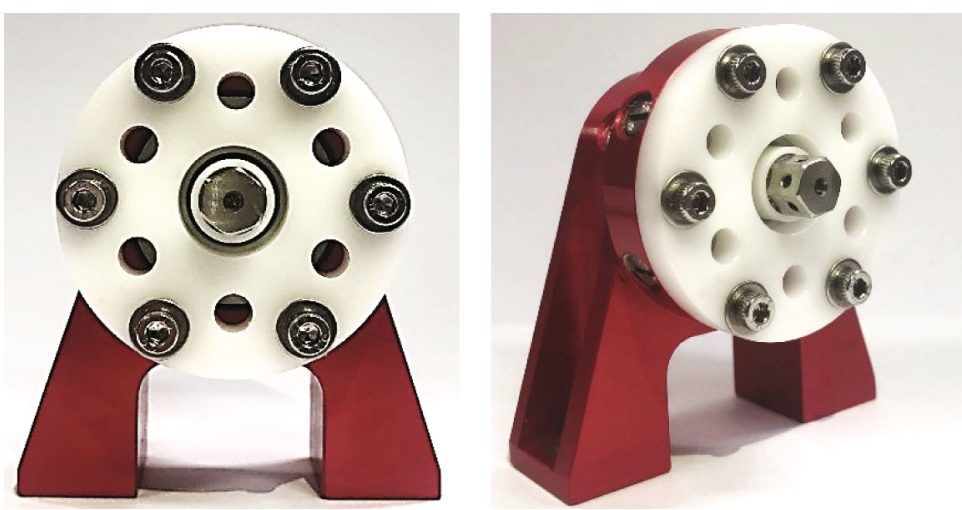

(b)

Figure 2: Configuration of the PLOVIS-II ((a) exploded view, (b) front and isometric view).

axial directional movements of the cooler in the launch phase.

Figure 3 shows the mechanical configuration of the cooler assembly integrated with thermal hardware of a heat pipe and radiator. The temperature of the cooler should be maintained under $35^{\circ} \mathrm{C}$ during its on-orbit operation. Two heat pipes with diameters of $9 \mathrm{~mm}$ are used for effective heat transfer from the cooler, with a heat dissipation of $35 \mathrm{~W}$ to the radiator for heat waste to deep space. The direction of the cooler accommodation and the heat pipe implementation 


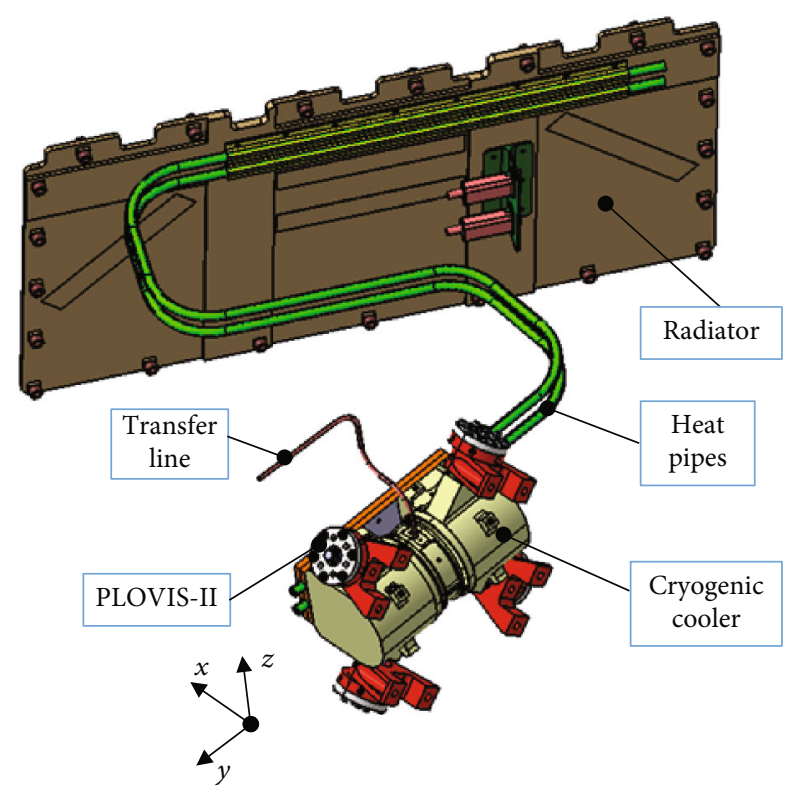

FIGURE 3: Thermal design configuration of cooler assembly with PLOVIS-II.

design shown in Figure 3 are effective for minimizing the possibility of increasing the microvibration under asymmetric temperature distribution on the cooler, even when one heat pipe fails [21]. The heat pipes should be designed to guarantee heat-transportation capability and isolator performance in an on-orbit environment. Therefore, to ensure the performance of the isolation system, a bent-shape heat pipes with relatively low stiffness are incorporated in the heat pipe design as shown in Figure 3, because the force transmitted through the heat pipe increases if the axial stiffness of the heat pipe is excessively high. In addition, this heat pipe design is effective for reducing the force transmitted to the cooler assembly, induced by the thermal deformation of the heat pipes, because the nominal position of the isolator is an important design parameter for the isolator performance.

Figure 4 shows a simplified mathematical model that explains the microvibration isolation strategy of the cooler assembly when using PLOVIS-II. In the case of the isolator based on the passive isolation system, it is difficult to predict the characteristics under the launch environment due to the nonlinear characteristics of PLOVIS-II induced by bumping and contact between the delrin materials parts. Actually, these nonlinear characteristics have limitations to mathematically simulate, so the design effectiveness of the PLOVIS-II in the launch environment was verified only experimentally. However, for the prediction of on-orbit microvibration isolation performance based on passive system, it is possible enough to explain using the proposed 1 degree of freedom mathematical model.

The mass of the cooler $(m)$ is supported by the spring elements of the heat pipe $\left(k_{h p}\right)$, transfer line $\left(k_{t l}\right)$, and PLOVISII, which is composed of a spring element of low-stiffness coil springs $\left(k_{s p}\right)$ and a dashpot element of an isolator $\left(c_{s p}\right)$. The

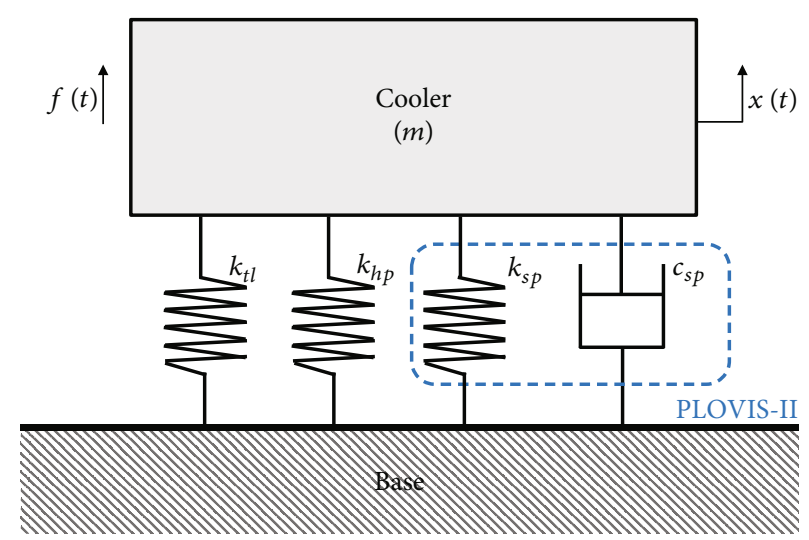

Figure 4: Simplified mathematical model of cooler assembly with PLOVIS-II.

disturbance force induced by cooler operation generates a microdisplacement $x(t)$ and can be expressed as

$$
f(t)=f_{0} e^{j \omega t}
$$

where $\omega$ is the driving frequency of the cooler and $f_{0}$ is the magnitude of the disturbance force. The on-orbit microvibration isolation strategy is based on the frequency decoupling between $\omega$ and the natural frequency of the cooler assembly of $\omega_{n}$, derived from

$$
\omega_{n}=\sqrt{k_{e q} / m},
$$

where $k_{e q}$ is the equivalent stiffness, defined as $k_{e q}=k_{h p}+k_{t l}$ $+k_{s p}$. The magnitude of the microvibrational force transmitted to the base is the critical path to meet a strict line-of-sight requirement of a high-resolution optical payload. Therefore, it is preferable to reduce the value of $k_{e q}$ as much as possible to avoid a structural resonance coupling between the structural eigenfrequency of the microvibration-sensitive optical payload and the driving frequency of $\omega$ from the cooler. The transmissibility function of disturbance force transmitted to the base can be expressed as follows:

$$
\operatorname{Transmissibility}(\mathrm{TR})=\sqrt{\frac{1+(2 \zeta \gamma)^{2}}{\left(1-\gamma^{2}\right)^{2}+(2 \zeta \gamma)^{2}}}
$$

where $\zeta$ is the damping ratio of the isolation system and $\gamma$ is the frequency ratio of $\omega / \omega_{n}$.

Figure 5 shows the calculated transmissibility (TR) with respect to an isolation system with $\omega_{n}$ values of $10 \mathrm{~Hz}$, $20 \mathrm{~Hz}$, and $30 \mathrm{~Hz}$. If we assume that the first eigenfrequency for the microvibration-sensitive structure of an optical payload is $45 \mathrm{~Hz}$, an isolation system with a lower value of $\omega_{n}$ exhibits considerably better isolation performance, owing to the frequency decoupling strategy. $\omega_{n}$ can be minimized by reducing the stiffness values of $k_{h p}, k_{t l}$, and $k_{s p}$ in the $y$ -direction. However, these values should be minimized properly by considering the design limitation of the hardware, 


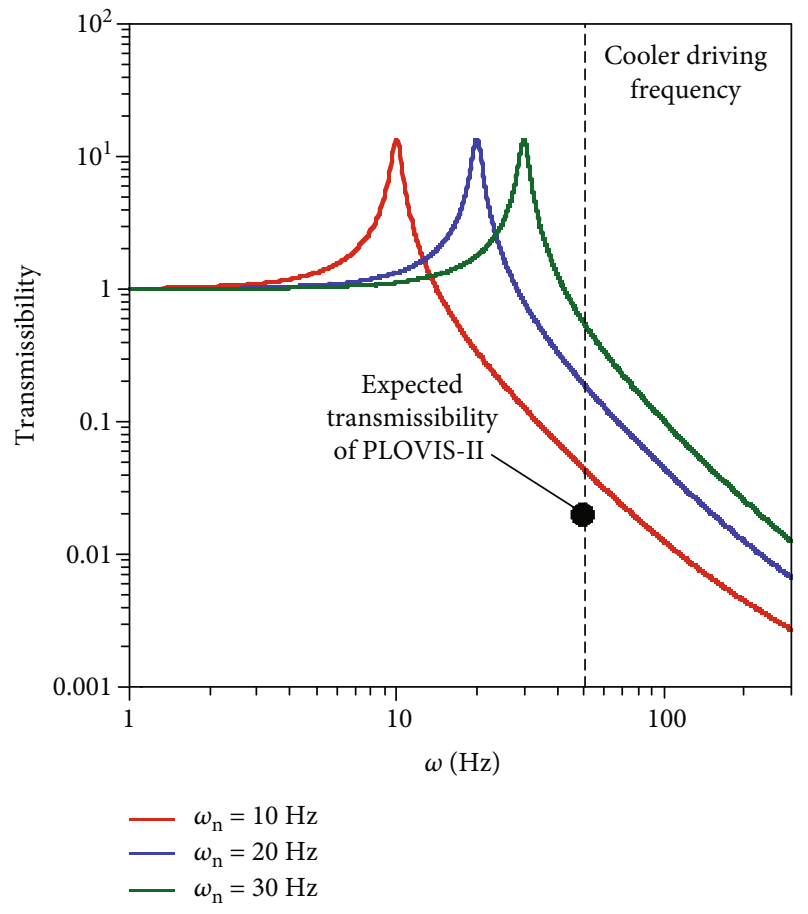

Figure 5: Transmissibility with respect to isolation system with various $\omega_{n}$ values.

including the heat pipes and transfer line integrated with the cooler assembly.

In designing heat pipes with regard to $k_{h p}$, first, the heat transportation capability of the heat pipes to unload a heat dissipation of $35 \mathrm{~W}$ from the cooler to the radiator should be considered. Two heat pipes with diameters of $9 \mathrm{~mm}$ were selected for the primary and redundant thermal design of the cooler. However, if the axial stiffness of the heat pipe is excessively high, such as for straight heat pipes, then the transmitted microvibration force through the stiffened heat pipes is increased. This is one of the reasons for deteriorated isolation performance owing to the increased stiffness value of $k_{e q}$ in a cooler isolation system. In addition, a larger force transmitted to the cooler isolation system, induced by the thermal deformation of a heat pipe is not permitted in an on-orbit environment, because maintaining the nominal position of the isolation system is important for ensuring satisfactory microvibration isolation performance. Therefore, the mechanical configuration of the heat pipes was selected such that the axial stiffness of the heat pipe $\left(k_{h p}\right)$ would be reduced as much as possible by implementing a bentshaped configuration that followed the bending-radius requirement of the heat pipe, as shown in Figure 3. In the transfer line design related to $k_{t}$, the same approach as the heat pipe was applied to reduce the stiffness of the transfer line on the $y$-axis as much as possible under a given length requirement of the transfer line. This guarantees the cooling performance of the cooler for achieving cryogenic temperatures on the focal plane of the imaging sensor.

The required stiffness value of $k_{s p}$ in the $y$-direction in terms of the isolator performance can be easily derived from the transmissibility of the base excitation vibration theory [22], specified in Eq. (3), if the cooler driving frequency and desired vibration reduction rate are given as design factors. This indicates that the stiffness in the lateral direction of the coil springs is related to the performance of the isolation system. However, the axial stiffness of the coil springs, which is higher than the lateral stiffness, mainly contributes to the nominal position recovery of the isolation system in orbit through the restoration force of the contracted and extended coil springs under the $1 \mathrm{~g}$ on-ground condition. Therefore, the combined stiffness value of $k_{s p}$ along the $x-z$ plane should be larger than the summation of the stiffness values of $k_{t l}$ and $k_{h p}$ on the $x$-and $z$-axes with some margins.

The predicted microvibration isolation performance of the newly designed PLOVIS-II system is plotted in Figure 5. The system parameters applied to the estimation are summarized in Table 1. $k_{s p}$ and $\zeta$ of the PLOVIS-II system were measured from a free-vibration test of a dummy cooler assembly under an on-orbit $0 \mathrm{~g}$ simulation condition. This is the same test setup described in Ref. [13]; although, the details of the test are not shown in this paper. The expected vibration reduction rate of PLOVIS-II is 32 times lower than that of the rigid condition without an isolation system when the driving frequency of $\omega$ is set to $50 \mathrm{~Hz}$.

\section{Design Validation of PLOVIS-II}

The effectiveness of the design of PLOVIS-II was validated through a launch vibration environment test and a microvibration measurement test. In this study, to confirm the performance enhancement of PLOVIS-II, an isolator with the same performance as the conventional PLOVIS (called PLOVIS-I) was additionally manufactured and tested.

To verify the feasibility of the newly designed PLOVIS-II under a launch vibration environment, both isolators were exposed to the qualification level of sine and random vibration tests. This test focused on the technical point of whether the new design of PLOVIS-II with a dual-spring configuration is effective for the attenuation of launch vibration loads to the cooler when compared with the conventional design.

To validate the performance enhancement of PLOVIS-II from the viewpoint of on-orbit microvibration isolation, a microvibration measurement test of both isolators was performed under the following test conditions: rigid, $1 \mathrm{~g}$ and simulated $0 \mathrm{~g}$. Finally, the position sensitivity of the isolator with respect to the aligned nominal position of the isolator which guarantees the best isolation performance was determined and investigated through a comparison with that of the conventional PLOVIS.

4.1. Launch Vibration Test. To confirm the effectiveness of the proposed isolator design, we performed a launch vibration test of the cooler assembly combined with the isolators, as shown in Figure 6. The conventional PLOVIS was also exposed to the vibration test for comparison with the newly designed PLOVIS-II. Figures 6(a) and 6(b) show the vibration test setups of PLOVIS-I and PLOVIS-II, respectively. In the test, the isolators were integrated with the dummy cooler having a mass and center of gravity similar to those 
TABLE 1: Basic characteristic values for PLOVIS-II.

\begin{tabular}{lc}
\hline Parameter & Value \\
\hline$m(\mathrm{~kg})$ & 3.8 \\
$\zeta$ & 0.037 \\
$k_{s p}(\mathrm{~N} / \mathrm{mm})$ & 8.6 \\
$k_{t l}(\mathrm{~N} / \mathrm{mm})$ & 0.57 \\
$k_{h p}(\mathrm{~N} / \mathrm{mm})$ & 1.05 \\
\hline
\end{tabular}

of the flight model of the cooler. The heat pipe and transfer line were not considered in the test, because they were already qualified in a unit-level test under allowable deflection ranges of $\pm 3 \mathrm{~mm}$ including $\pm 1 \mathrm{~mm}$ margin with respect to the allowable deflection range of the isolation system implemented with a displacement limiter. The accelerometers were attached to the center of gravity of the dummy cooler and the bottom of the support brackets. The qualification levels of the sine and random vibration test specifications applied to the design validation of the isolators are summarized in Tables 2 and 3 , and the test-axes are described in Figures 6.

Figures $7(\mathrm{a})$ and $7(\mathrm{~b})$ show the representative sine vibration test results for PLOVIS-I and PLOVIS-II during $z$-axis excitation. The acceleration response of the cooler on the $z$-axis gradually increased as the excitation frequency increased. The highest measured acceleration of the cooler with PLOVIS- II for the $z$-axis response was $20.9 \mathrm{~g}$, which is $45 \%$ lower than the cooler design load of $46.2 \mathrm{~g}$. This is also a lower value than the $25 \mathrm{~g}$ obtained from PLOVIS-I. In addition, the responses from PLOVIS-II showed considerably less chattering of acceleration on all axes than PLOVIS-I. The test results indicate that the presence of the moving plates supported by the high-stiffness coil-springs of PLOVIS-II is effective for attenuating the launch vibration loads when the mechanical shaft cover bumps the moving plates. This is in contrast to PLOVIS-I, where the mechanical shaft cover directly bumps the displacement limiter.

Figures 8(a) and 8(b) show the representative random vibration test results for PLOVIS-I and PLOVIS-II during $z$ -axis excitation. The results showed that the acceleration in a higher frequency range is strongly damped out because of the vibration energy dissipation induced by the contact and slip between the plastic elements of the isolation system, as intended with the design. A maximum acceleration of 5.1 $\mathrm{g}_{\mathrm{rms}}$ in the $z$-axis sensor response of PLOVIS-II was observed with respect to the random test input of $15.4 \mathrm{~g}_{\mathrm{rms}}$. This value is $66 \%$ lower than the value of $10.8 \mathrm{~g}_{\mathrm{rms}}$ obtained from the PLOVIS-I, because the combination of high-stiffness coilsprings in the PLOVIS-II is effective for reducing the transmitted launch loads to the dummy cooler. For the same reason, the accelerometer response on the support bracket of PLOVIS-II showed a 50\% higher $\mathrm{g}_{\text {rms }}$ reduction than that of PLOVIS-I. Table 4 summarizes the launch vibration test results on each test axis as obtained from both isolators. The sine vibration test results from PLOVIS-II showed a slightly lower or higher vibration reduction performance than that of PLOVIS-I. However, the combined $g_{\text {rms }}$ values for random vibration tests on the $x$-, $y$-, and $z$-axis showed performance improvements of $46 \%, 43 \%$, and $52 \%$, respectively, when applying PLOVIS-II. Furthermore, PLOVIS-II also showed performance improvements of $40 \%, 30 \%$, and $34 \%$ with respect to the reduction of the launch loads transmitted to the support brackets on the $x$-, $y$-, and $z$-axis, respectively.

To evaluate the variation in basic characteristics of PLOVIS-II, such as the natural frequency and damping ratio after the completion of the launch vibration tests, a free-vibration test was performed under the $0 \mathrm{~g}$ condition. This was simulated by hanging the cooler using rubber strings. This approach was adopted, because it is difficult to measure the characteristic variation through low-level sine sweep tests by using a vibration shaker because of the nonlinear characteristics generated when the isolator is pressed by the gravitational force of the cooler under $1 \mathrm{~g}$ condition. The test results summarized in Table 5 indicate that the natural frequency of the cooler assembly was almost the same as those measured before the vibration tests. Figure 9 shows the configuration of the coil-springs of PLOVIS-II after the launch vibration tests. Through a visual inspection, we confirmed that there were no mechanical failures of the springs, such as plastic deformation or fracture. These test and inspection results indicate that PLOVIS-II proposed in this study ensures the structural safety of the cooler and improves the vibration attenuation performance compared with the conventional PLOVIS-I.

4.2. Microvibration Measurement Test. To confirm the effectiveness of PLOVIS-II in terms of the enhancement of microjitter isolation performance compared with the conventional PLOVIS-I, an isolation performance test using a dummy cooler was performed on a microvibration measurement system. The test setup is shown in Figure 10(a). A moving magnet linear actuator (NCM08-17-050-2LB, H2W Technologies) was integrated in the dummy cooler to simulate the microvibration characteristics of a pulse-tube-type cooler. The force level generated by the dummy cooler in main excitation axis ( $y$-axis) of the cooler was $1.11 \mathrm{~N}$ at a main driving frequency of $50 \mathrm{~Hz}$. The disturbance force transmitted from the dummy cooler to the bottom plate was measured using three-axis load cells (MC15-3A-100, DACELL Co. Ltd.). To simulate the axial ( $y$-axis) directional stiffness of the heat pipe and to simulate the lateral ( $y$-axis) and gravity ( $x$-axis) directional stiffness of the transfer line, simulated springs for the heat pipe and transfer line stiffness were used in the test as shown in Figure 10(b) (enlarged view of cooler assembly).

The test cases for the microvibration measurement condition were defined as follows: (a) rigidly clamped condition for measuring the vibration level of the cooler itself by applying a rigid bracket; (b) with an isolator under a simulated $0 \mathrm{~g}$ condition; and (c) with an isolator under a $1 \mathrm{~g}$ condition, where a static force of $37.24 \mathrm{~N}$ was induced along the gravitational direction owing to the cooler mass.

The case (a) is implemented by clamping the bracket as shown in Figure 11(a). In case (b), the cooler was placed at the nominal position of the isolator by using a $1 \mathrm{~g}$ compensation device, as shown in Figure 11(b), where the desirable 


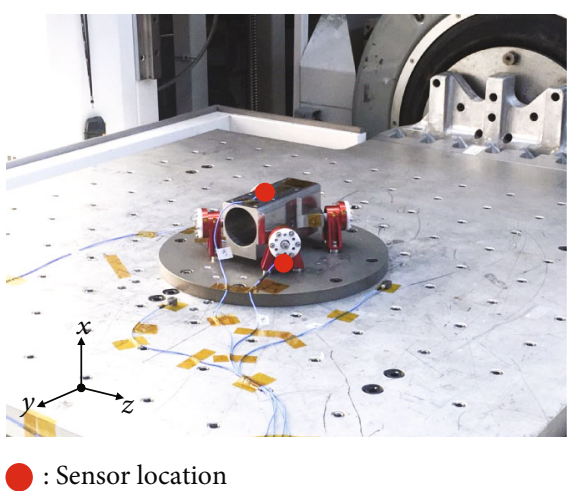

(a)

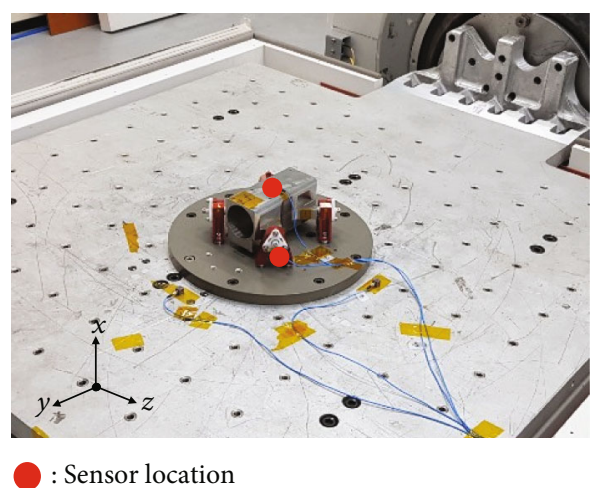

(b)

FIgure 6: Launch vibration test set-up ((a) PLOVIS-II, (b) PLOVIS-I).

TABLE 2: Specification of sine vibration test.

\begin{tabular}{|c|c|c|c|c|}
\hline Item & \multicolumn{4}{|c|}{ Specification } \\
\hline Axis & \multicolumn{4}{|c|}{$x, y, z$} \\
\hline \multirow[t]{3}{*}{ Sweep rate } & \multicolumn{4}{|c|}{$2 \mathrm{oct} / \mathrm{min}$} \\
\hline & & & & \\
\hline & Frequency $(\mathrm{Hz})$ & Acceleration (g) & Frequency $(\mathrm{Hz})$ & Acceleration (g) \\
\hline \multirow[t]{3}{*}{ Acceleration profile } & $5 \sim 12$ & $\pm 8.1 \mathrm{~mm}$ & $5 \sim 12$ & $\pm 9.2 \mathrm{~mm}$ \\
\hline & $12 \sim 30$ & 6.5 & $12 \sim 30$ & 9 \\
\hline & $30 \sim 100$ & 3 & $30 \sim 100$ & 6.5 \\
\hline
\end{tabular}

TABLE 3: Specification of random vibration test.

\begin{tabular}{lcc}
\hline Item & \multicolumn{2}{c}{ Specification } \\
\hline Axis & \multicolumn{2}{c}{$x, y, z$} \\
\hline RMS acceleration & $15.4 \mathrm{~g}_{\mathrm{rms}}$ \\
\hline Duration & \multicolumn{2}{c}{$2 \mathrm{~min}$} \\
\hline \multirow{3}{*}{ Frequency $(\mathrm{Hz})$} & PSD acceleration $\left(\mathrm{g}^{2} / \mathrm{Hz}\right)$ \\
& 20 & 0.057 \\
Acceleration profile & 70 & 0.2 \\
& 700 & 0.2 \\
& 2000 & 0.035 \\
\hline
\end{tabular}

isolation performance could be ensured. Case (c) was the unexpected worst case for on-orbit operations but was performed to qualitatively evaluate the microvibration isolation performance when the cooler shifted out of the lowstiffness range for reasons such as misalignment of the heat pipe and IR sensor module or unexpected thermal distortion from the heat pipe. In such a case without the $1 \mathrm{~g}$ compensation device, the low-stiffness coil-springs employed in PLOVIS-I and PLOVIS-II were compressed and extended by the gravitational force of the cooler assembly. However, these isolators had different mechanical supporting configurations. For example, the cooler with PLOVIS-II was supported by a moving plate combined with high-stiffness coilsprings, as shown in Figure 11(c). However, the cooler with
PLOVIS-I directly contacted the displacement limiter that was integrated into the support bracket, as shown in Figure 11(d). Thus, the disturbance force of the cooler was directly transferred to the base plate through the support bracket without any reduction.

Figure 12 shows the test results obtained from case (a) for the $x-, y$-, and $z$-axes. A maximum peak force of $1.11 \mathrm{~N}$ at $50 \mathrm{~Hz}$ was observed in the longitudinal direction of the $y$ -axis. Otherwise, the disturbance levels for the lateral directions, i.e., the $x$ - and $z$-axes, were relatively small compared with that of the $y$-axis. This means that these lateral directions are not critical axes in terms of the pointing stability of the observation satellite.

Figure 13 shows the test results obtained from case (b). A maximum peak force of $0.04 \mathrm{~N}$ was observed on $y$-axis, which is a considerably lower value than that of case (a). Here, the microvibration level of the cooler was significantly reduced, by a factor of 29 . This is almost the same value as the predicted value of 32 from the transmissibility curve of the isolation system shown in Figure 5. Moreover, the disturbances in the high-frequency region on all axes were effectively reduced because of the frequency decoupling strategy applied in the isolator design.

Figure 14 shows the test results obtained from case (c). The maximum peak force was $0.46 \mathrm{~N}$ along the $y$-axis, which is also a lower value than that of case (a). In this manner, the transmitted force level was reduced by a factor of $2.3 \mathrm{com}$ pared with case (a), because the cooler was still supported by the moving plate with a high-stiffness coil spring, unlike 


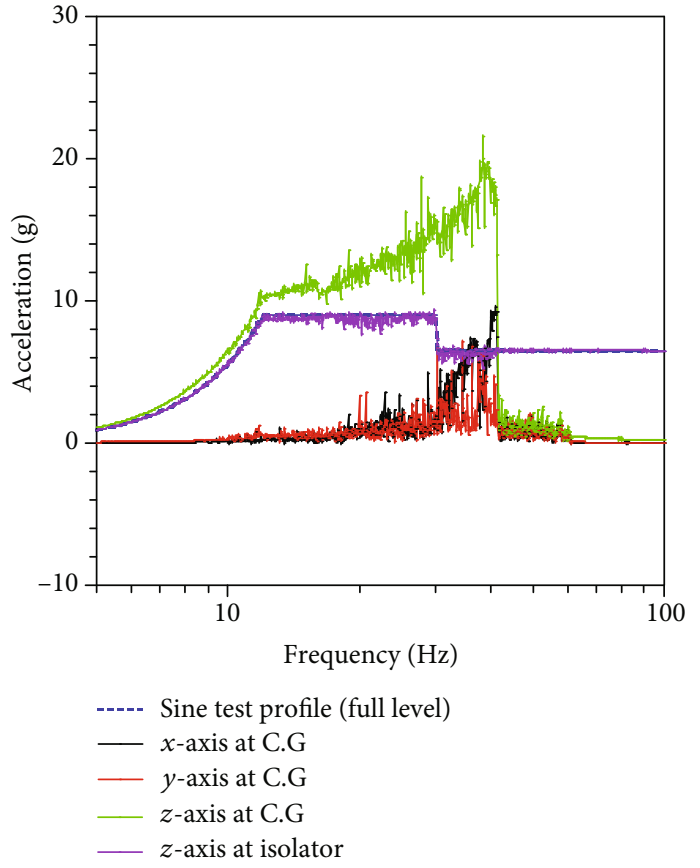

(a)

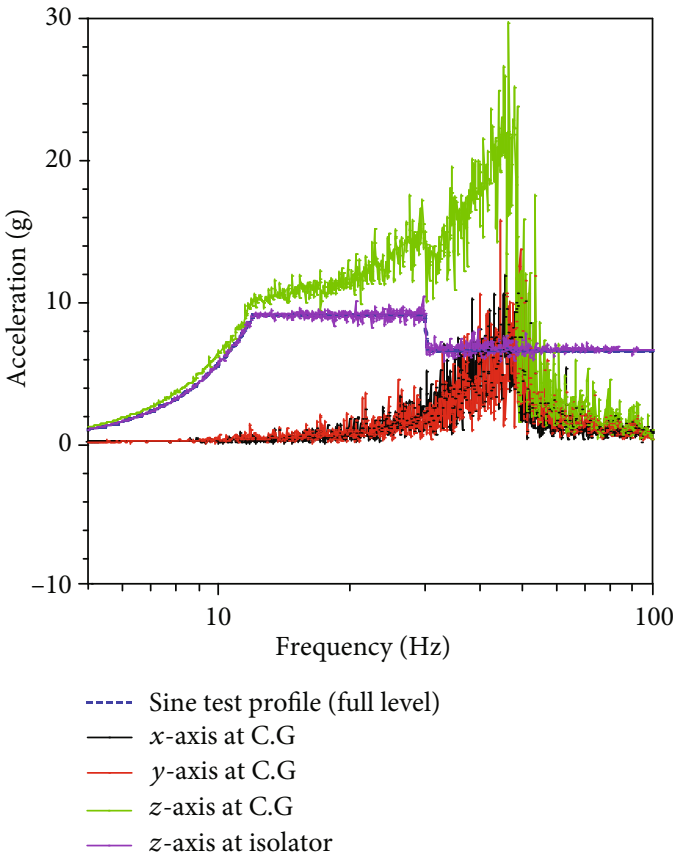

(b)

Figure 7: Sine vibration test results for $z$-axis ((a) PLOVIS-II, (b) PLOVIS-I).

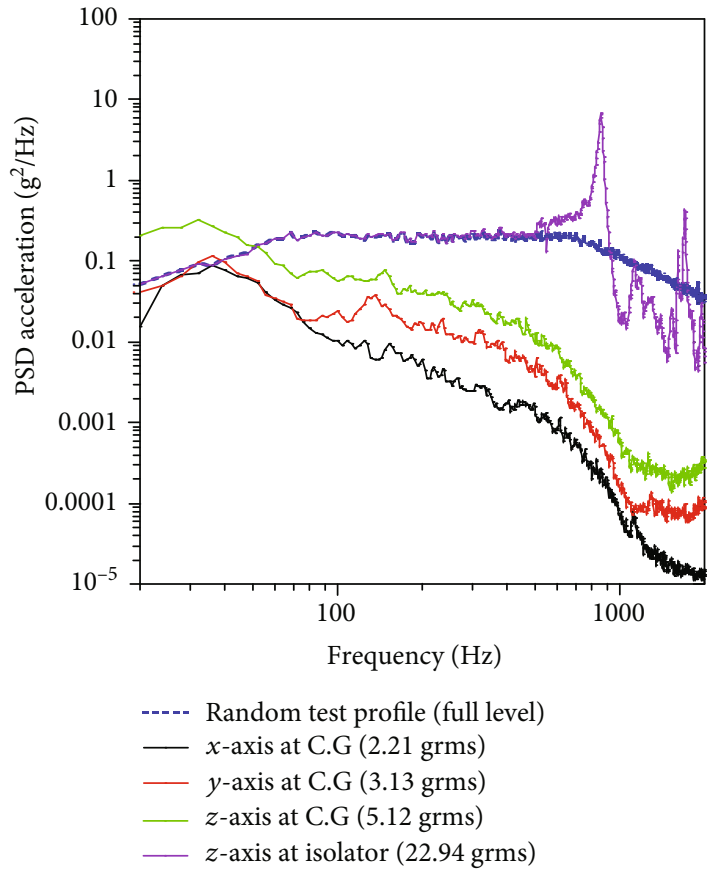

(a)

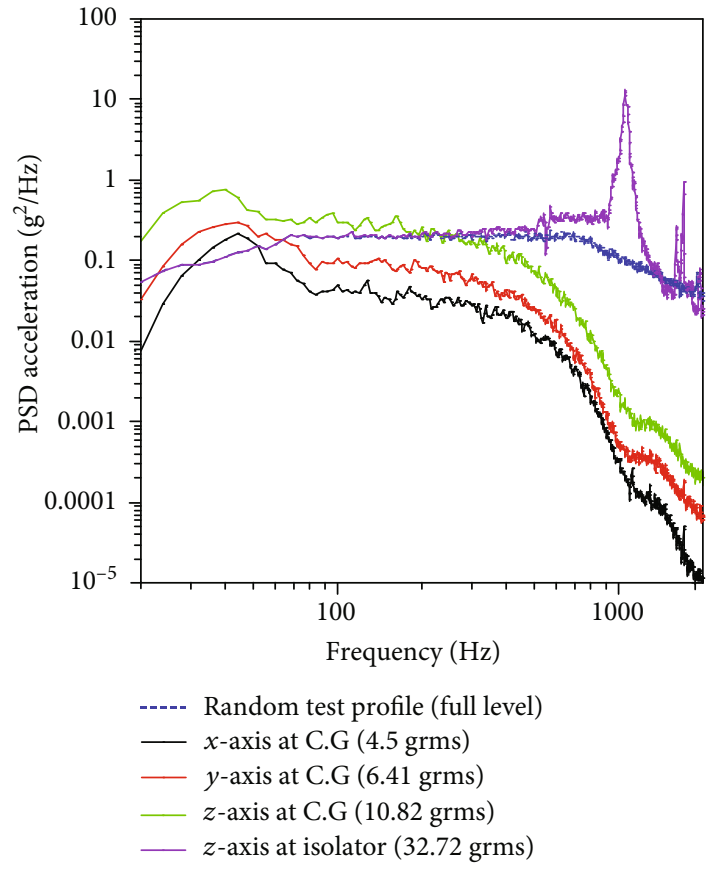

(b)

FIGURE 8: Random vibration test results for $z$-axis ((a) PLOVIS-II, (b) PLOVIS-I).

in PLOVIS-I, where the microvibration of the cooler was directly transmitted to the bottom plate through the support bracket as described above.

Table 6 summarizes the microvibration measurement test results for PLOVIS-II. The results for PLOVIS-I are also summarized in the table for comparison. Under the $0 \mathrm{~g}$ con- dition, it can be noted that both isolators showed almost the same isolation performance for all axes, because these isolators support the cooler with the same low-stiffness configuration. More specifically, the cooler with PLOVIS-II could stay within the nominal position without any contact between the mechanical shaft of the cooler and the moving plate. Under 
TABLE 4: Summary of launch vibration test results.

\begin{tabular}{|c|c|c|c|c|c|c|c|c|}
\hline \multirow{3}{*}{ Excitation axis } & \multicolumn{4}{|c|}{ PLOVIS-I } & \multicolumn{4}{|c|}{ PLOVIS-II } \\
\hline & \multirow[b]{2}{*}{ Sine $(g)$} & \multirow[t]{2}{*}{ C.G } & & ort bracket & \multirow[b]{2}{*}{ Sine $(\mathrm{g})$} & C.G & & ort bracket \\
\hline & & & Rando & & & \multicolumn{3}{|c|}{ Random (g $\left.g_{\text {rms }}\right)$} \\
\hline \multirow{4}{*}{$x$} & \multirow{4}{*}{14.19} & $x$ & 11.66 & 16.81 & \multirow{4}{*}{17.92} & $x$ & 7.08 & 15.02 \\
\hline & & $y$ & 10.16 & 23.74 & & $y$ & 6.04 & 11.16 \\
\hline & & $z$ & 21.19 & 24.39 & & $z$ & 10.52 & 12.59 \\
\hline & & Comb. & 26.23 & 37.09 & & Comb. & 14.04 & 22.55 \\
\hline \multirow{4}{*}{$y$} & \multirow{4}{*}{13.82} & $x$ & 3.99 & 18.21 & \multirow{4}{*}{12.00} & $x$ & 4.07 & 15.40 \\
\hline & & $y$ & 6.57 & 30.47 & & $y$ & 4.75 & 23.28 \\
\hline & & $z$ & 8.63 & 26.25 & & $z$ & 2.05 & 12.87 \\
\hline & & Comb. & 11.55 & 44.14 & & Comb. & 6.58 & 30.73 \\
\hline \multirow{4}{*}{$z$} & \multirow{4}{*}{24.67} & $x$ & 4.50 & 17.01 & \multirow{4}{*}{20.90} & $x$ & 2.21 & 12.01 \\
\hline & & $y$ & 6.41 & 28.11 & & $y$ & 3.13 & 15.84 \\
\hline & & $z$ & 10.82 & 32.72 & & $z$ & 5.12 & 22.94 \\
\hline & & Comb. & 13.35 & 46.36 & & Comb. & 6.39 & 30.35 \\
\hline
\end{tabular}

TABLE 5: Free vibration test results before and after launch vibration tests.

\begin{tabular}{lccc}
\hline Parameter & Before test & After test & Variation (\%) \\
\hline Natural frequency $(\mathrm{Hz})$ & 7.7 & 7.8 & 1.28 \\
Damping ratio & 0.037 & 0.03 & - \\
\hline
\end{tabular}

the $1 \mathrm{~g}$ condition, however, PLOVIS-II showed enhanced isolation performance compared with PLOVIS-I. For example, PLOVIS-I exhibited a value of $1.08 \mathrm{~N}$, and this value is almost the same as that obtained from the rigid condition. By contrast, PLOVIS-II exhibited $0.46 \mathrm{~N}$, which is 2.4 times lower than that under the rigid condition. These results indicate that PLOVIS-II has an unsusceptible position sensitivity that is 2.3 times that of PLOVIS-I, as intended with the design, even though PLOVIS-II was under the worst unexpected conditions during actual on-orbit operation. In terms of the root mean square (RMS) force value under the $1 \mathrm{~g}$ condition, PLOVIS-II exhibited a value that was 3.2 times lower than that of PLOVIS-I, because the high-frequency harmonic disturbances, coupled with the structural modes of the isolation system, were also effectively isolated with PLOVIS-II.

4.3. Position Sensitivity Test. To evaluate the position sensitivity of the isolator when the cooler assembly is shifted out of the nominal position, we performed a position sensitivity test. The alignment requirement of the heat pipe and IR sensor module integration to maintain the desirable isolation performance can also be derived through this test. In the test, enforced translational displacement was intentionally applied to shift the position of the cooler on each axis. The test was performed by shifting the cooler assembly in $0.5 \mathrm{~mm}$ increments, because it is difficult to perform the test with smaller increments due to the limitation of test setup.
Also, the performance variation of position sensitivity is clearly distinguishable even though it uses the $0.5 \mathrm{~mm}$ increments.

Figures 15(a) and 15(b) show the representative position sensitivity test results of the cooler assembly with PLOVIS-I and PLOVIS-II for various shifted positions of the isolator along the $y$-axis. The test results for the peak force value at the main cooler driving frequency of $50 \mathrm{~Hz}$ and the RMS force value gradually increased as the cooler shifted out of its nominal aligned position. Both isolators showed almost the same test results within a $1 \mathrm{~mm}$ displacement range, because they had similar supporting conditions of the lowstiffness coil springs. However, at a $1.5 \mathrm{~mm}$ shifted position, the peak force of PLOVIS-II was approximately 3.1 times lower than that of PLOVIS-I, owing to the different boundary conditions of PLOVIS-I, as mentioned above. This also leads to better isolation performance by minimizing the high frequency-harmonic disturbances induced by coupling with the structural modes of the cooler assembly, resulting in substantially lower RMS values than those of PLOVIS-I.

Table 7 summarizes the results of the position sensitivity tests on each axis. These test results indicate that PLOVIS-II is less position-sensitive than the conventional PLOVIS-I, because it showed much more stable microvibration isolation performance at various shifted positions on all axes. Therefore, the application of the proposed PLOVIS-II is effective for mitigating the strict alignment requirement for heat pipes and the IR detector. This is preferable reducing the potential risk, considering the system reliability.

\section{Conclusion}

In this study, to improve the capability of the conventional PLOVIS in terms of position sensitivity and launch vibration reduction, a new version of a dual coil-spring-type passive isolator system, called PLOVIS-II, was proposed and investigated. To confirm the feasibility of the isolator design under 


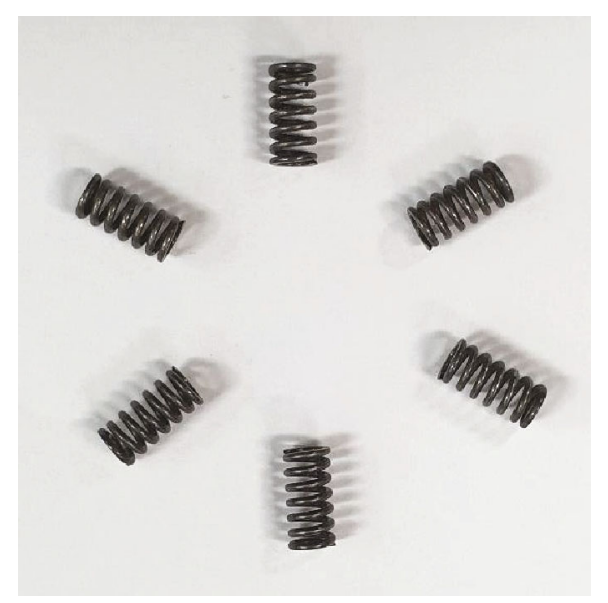

(a)

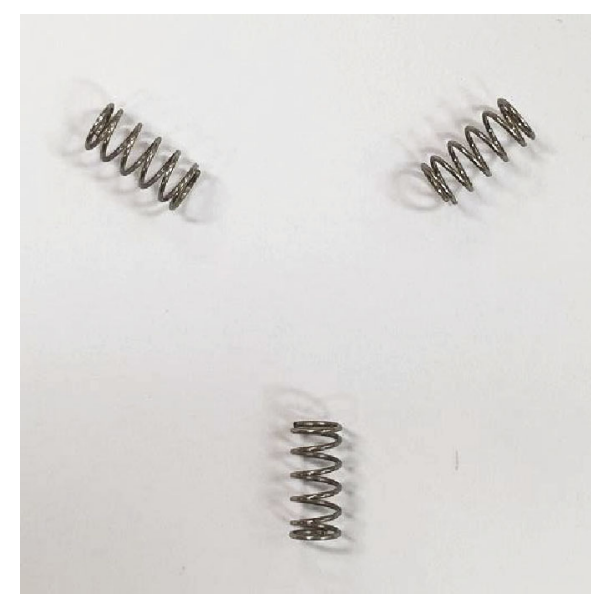

(b)

FIGURE 9: Visual inspection results of coil-springs of PLOVIS-II after launch vibration tests ((a) high-stiffness coil-springs, (b) low-stiffness coil-springs).

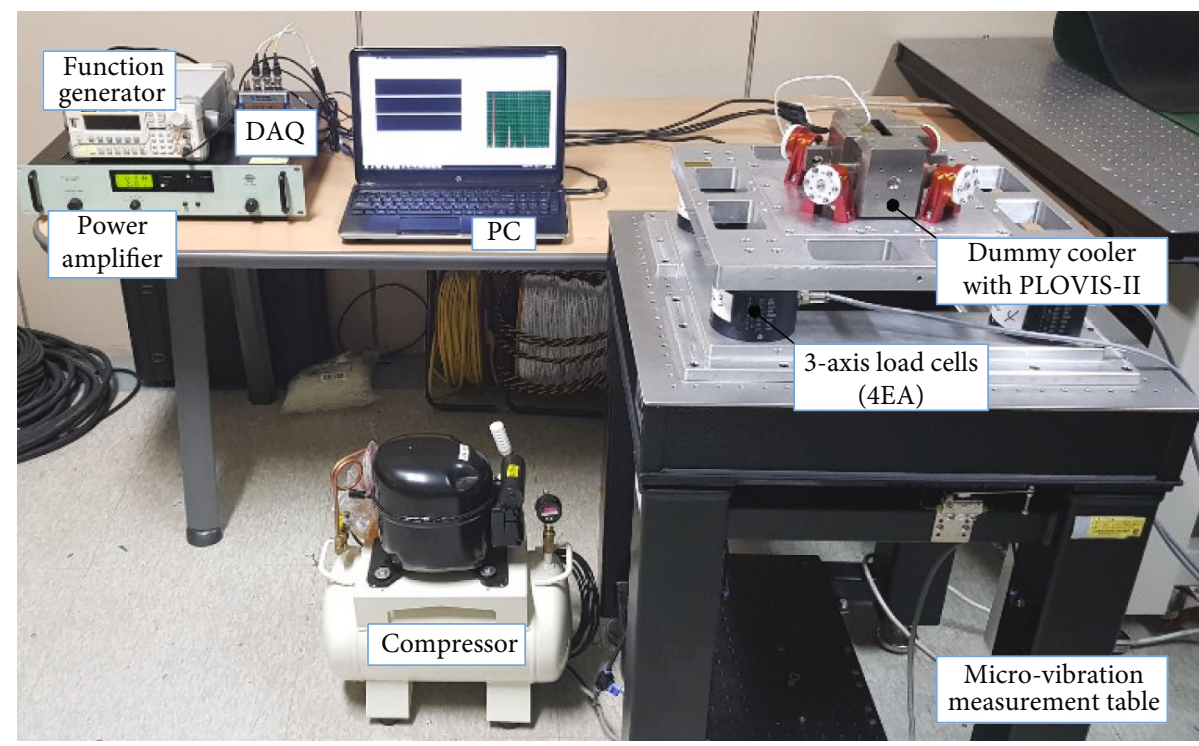

(a)

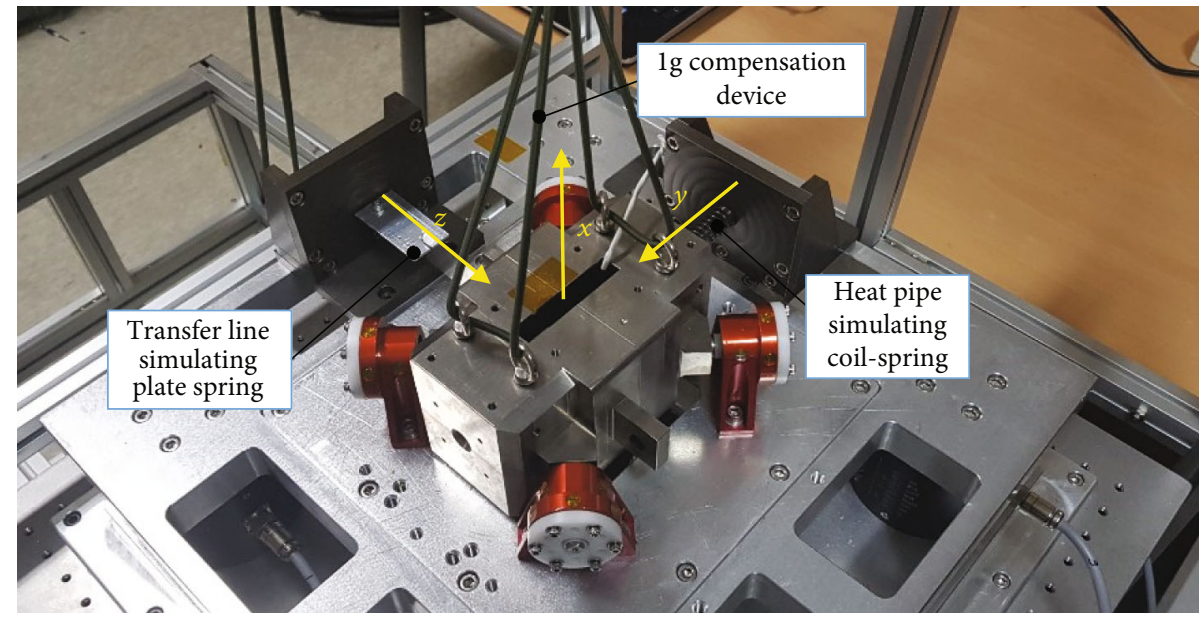

(b)

Figure 10: Microvibration measurement test set-up ((a) overall view, (b) enlarged view). 


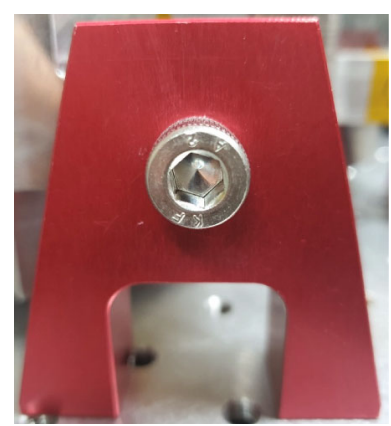

(a)

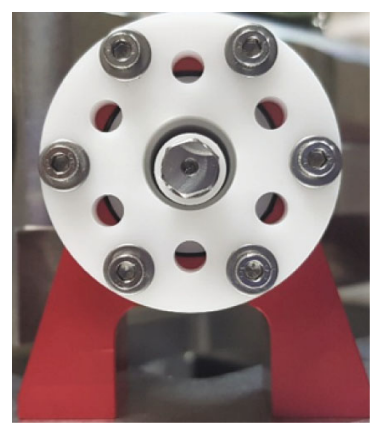

(c)

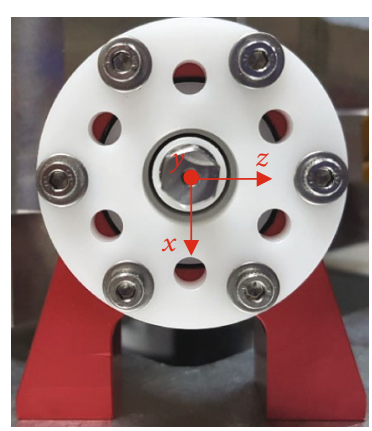

(b)

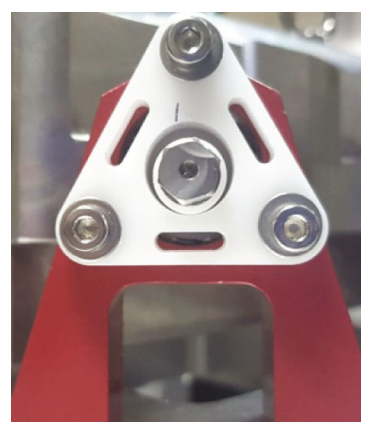

(d)
Figure 11: Cooler position for each case ((a) rigidly clamping condition (b) nominal position under $0 \mathrm{~g}$ (PLOVIS-II), (c) shifted position under $1 \mathrm{~g}$ (PLOVIS-II), (d) shifted position under $1 \mathrm{~g}$ (PLOVIS-I)).
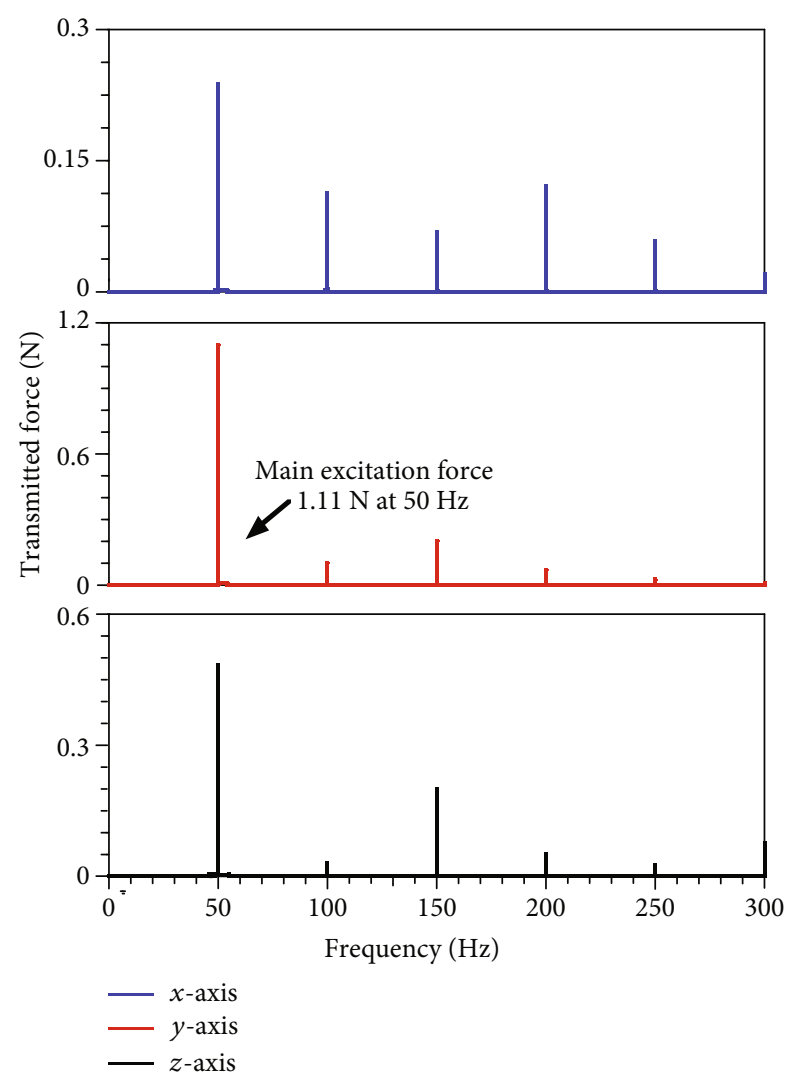

FIGURE 12: Microvibration measurement test results under rigidly clamped condition.
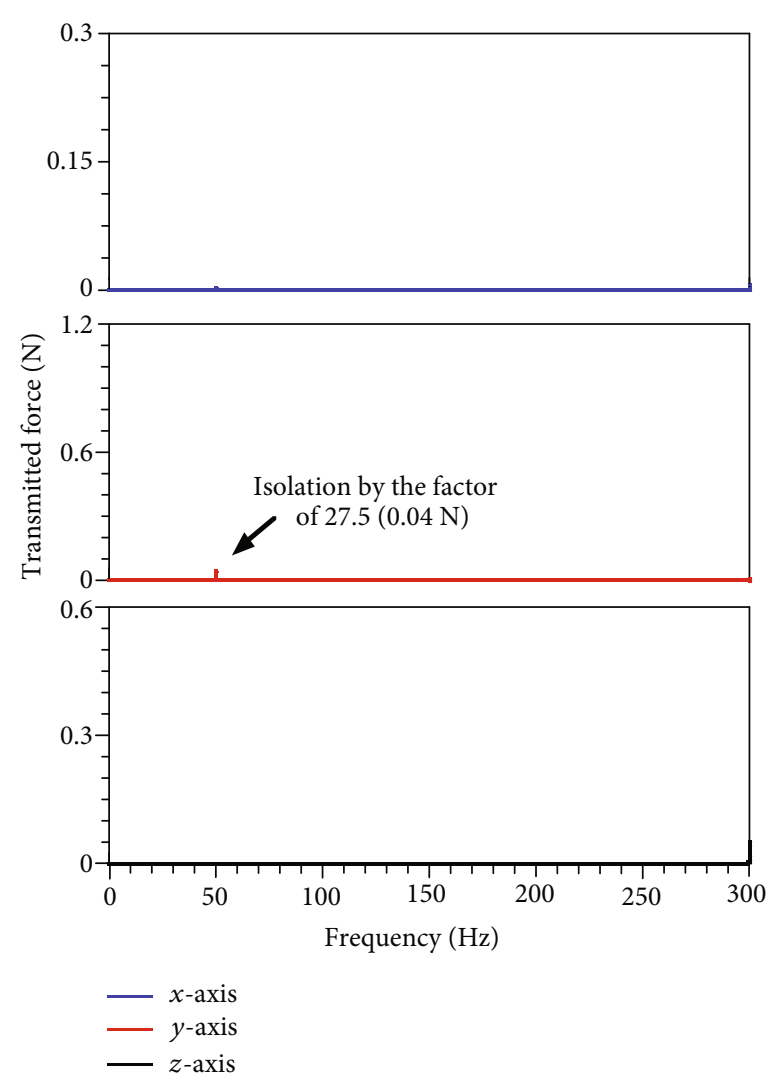

FIgURE 13: Microvibration measurement test results under $0 \mathrm{~g}$ condition.
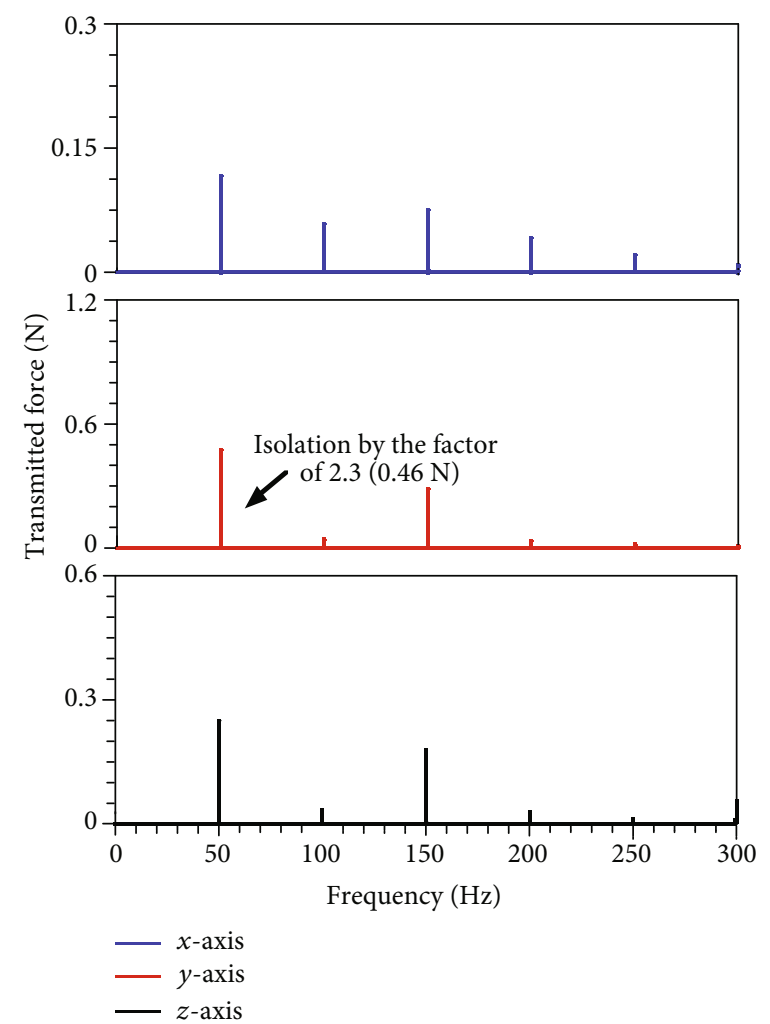

FIgURE 14: Microvibration measurement test results under $1 \mathrm{~g}$ condition. 
TABLE 6: Summary of microvibration measurement test results.

\begin{tabular}{|c|c|c|c|c|c|c|c|c|c|c|c|c|c|c|c|}
\hline \multirow{2}{*}{ Parameter } & \multirow{2}{*}{\multicolumn{3}{|c|}{ Rigid }} & \multicolumn{6}{|c|}{ PLOVIS-I } & \multicolumn{6}{|c|}{ PLOVIS-II } \\
\hline & & & & & $0 \mathrm{~g}$ & & & $1 \mathrm{~g}$ & & & $0 \mathrm{~g}$ & & & $1 \mathrm{~g}$ & \\
\hline Axis & $x$ & $y$ & $z$ & $x$ & $y$ & $z$ & $x$ & $y$ & $z$ & $x$ & $y$ & $z$ & $x$ & $y$ & $z$ \\
\hline Peak value $(\mathrm{N})$ & 0.21 & 1.11 & 0.48 & 0.003 & 0.034 & 0.004 & 0.04 & 1.08 & 0.2 & 0.004 & 0.04 & 0.003 & 0.13 & 0.48 & 0.10 \\
\hline RMS value $\left(\mathrm{N}_{\mathrm{rms}}\right)$ & 0.16 & 0.75 & 0.38 & 0.045 & 0.044 & 0.013 & 0.04 & 0.85 & 0.17 & 0.06 & 0.02 & 0.025 & 0.18 & 0.26 & 0.067 \\
\hline
\end{tabular}

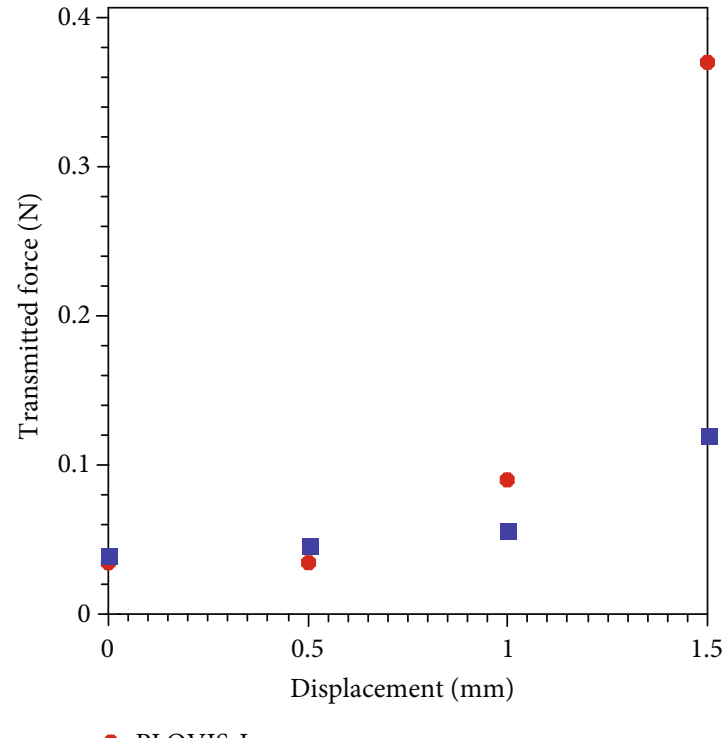

PLOVIS-I

- PLOVIS-II

(a)

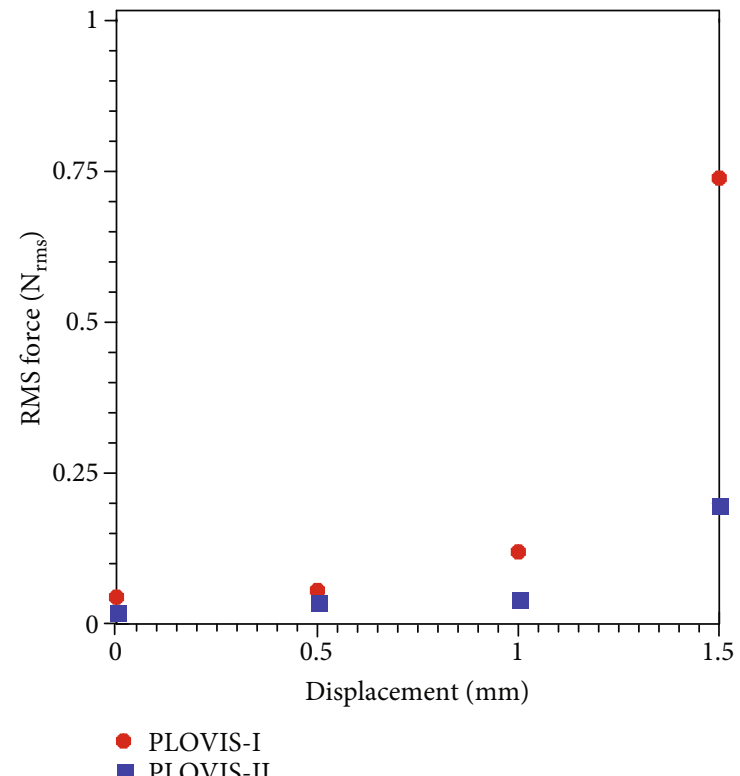

(b)

FIGURE 15: Position sensitivity test results for $y$-axis ((a) transmitted force, (b) RMS force).

TABLE 7: Summary of position sensitivity test results.

\begin{tabular}{|c|c|c|c|c|c|c|c|c|}
\hline \multirow{2}{*}{ Shifted position (mm) } & \multicolumn{4}{|c|}{ PLOVIS-I } & \multicolumn{4}{|c|}{ PLOVIS-II } \\
\hline & 0 & 0.5 & 1.0 & 1.5 & 0 & 0.5 & 1.0 & 1.5 \\
\hline \multicolumn{9}{|l|}{ Peak value $(\mathrm{N})$} \\
\hline$x$ & 0.034 & 0.039 & 0.065 & 0.24 & 0.04 & 0.044 & 0.063 & - \\
\hline$y$ & 0.034 & 0.035 & 0.084 & 0.37 & 0.04 & 0.047 & 0.057 & 0.12 \\
\hline$z$ & 0.034 & 0.043 & 0.050 & 0.15 & 0.04 & 0.046 & 0.047 & - \\
\hline \multicolumn{9}{|l|}{ RMS value $\left(\mathrm{N}_{\mathrm{rms}}\right)$} \\
\hline$x$ & 0.044 & 0.344 & 0.107 & 0.80 & 0.02 & 0.049 & 0.080 & - \\
\hline$y$ & 0.044 & 0.057 & 0.120 & 0.74 & 0.02 & 0.036 & 0.041 & 0.19 \\
\hline$z$ & 0.044 & 0.350 & 0.071 & 0.66 & 0.02 & 0.033 & 0.049 & - \\
\hline
\end{tabular}

the launch vibration environment, the proposed system was exposed to the qualification-level of sine and random vibration tests. The test results indicated that PLOVIS-II ensured the structural safety of the cooler assembly under the qualification level of launch vibration loads and also improved the vibration attenuation performance compared with PLOVISI. The microvibration test results of PLOVIS-II in a simulated on-orbit $0 \mathrm{~g}$ condition demonstrated that the microvibration was significantly reduced, by a factor of 29 , compared with that of a rigidly clamped cooler. In addition, a position sensi- tivity test demonstrated that PLOVIS-II is less sensitive than PLOVIS-I to the aligned position of the isolator.

\section{Data Availability}

The data used to support the findings of this study are available from the corresponding author upon request.

\section{Conflicts of Interest}

The authors declare that they have no conflicts of interest. 


\section{Acknowledgments}

This research was supported by the Space Technology Development Program of the National Research Foundation of Korea (NRF) and funded by the Ministry of Science, ICT (MSIT) (NRF 2020M1A3A4A07052211).

\section{References}

[1] D. G. Gilmore, Spacecraft Thermal Control Handbook: Fundamental Technologies, The Aerospace Press, 2nd edition, 2002.

[2] R. Radebaugh, "Pulse tube Cryocoolers for cooling infrared sensors," in Proceedings Volume 4130, Infrared Technology and Applications XXVI, pp. 363-379, San Diego, CA, USA, December 2000.

[3] R. G. Ross, "Cryocooler reliability and redundancy considerations for long-life space missions," in Cryocoolers 11, R. G. Ross, Ed., pp. 637-648, Springer, Boston, MA, USA, 2002.

[4] A. M. Veprik, V. I. Babitsky, N. Pundak, and S. V. Riabzev, "Vibration control of linear Split Stirling cryogenic cooler for airborne infrared application," Shock and Vibration, vol. 7, no. 6, pp. 363-379, 2000.

[5] G. C. Richard, J. M. Sullivan, A. Das et al., "Vibration isolation and suppression system for precision payloads in space," Smart Materials and Structures, vol. 8, no. 6, pp. 798-812, 1999.

[6] M. J. Ellis, T. T. Luong, L. Shaw et al., "Development of a miniature Cryocooler system for Cubesats," Cryocoolers, vol. 18, pp. 329-339, 2014.

[7] S. V. Riabzev, A. M. Veprik, H. S. Vilenchik, N. Pundak, and E. Castiel, "Vibration-free Stirling Cryocooler for high definition microscopy," Cryogenics, vol. 49, no. 12, pp. 707-713, 2009.

[8] A. Veprik, S. Zechtzer, N. Pundak, S. Riabzev, C. Kirckonnel, and J. Freeman, "Low vibration microminiature Split Stirling cryogenic cooler for infrared aerospace applications," AIP Conference Proceedings, vol. 1434, pp. 1473-1480, 2012.

[9] D. Kamesh, R. Pandiyan, and A. Ghosal, "Passive vibration isolation of reaction wheel disturbances using a low frequency flexible space platform," Journal of Sound and Vibration, vol. 331, no. 6, pp. 1310-1330, 2012.

[10] Y. Takei, S. Yasuda, K. Ishimura et al., "Vibration Isolation System for Cryocoolers of Soft X-ray Spectrometer (SXS) Onboard ASTRO-H (Hitomi)," in Proceedings Volume 9905, Space Telescopes and Instrumentation 2016: Ultraviolet to Gamma Ray; 99050X, Edinburgh, UK, July 2016.

[11] A. Veprik, S. Zechtzer, and N. Pundak, "Split Stirling Linear Cryogenic Cooler for A New Generation of High Temperature Infrared Imagers," in Proceedings Volume 7660, Infrared Technology and Applications XXXVI, Orlando, FL, USA, May 2010.

[12] S. C. Kwon, S. H. Jeon, and H. U. Oh, "Performance investigation of a novel Pseudoelastic SMA mesh washer gear wheel with micro-jitter attenuation capability," Smart Materials and Structure, vol. 25, no. 5, article 055004, 2016.

[13] S. Takuma and S. Sakai, "Performance of Contactless Micro Vibration Isolator Using Flux Pinning Effect," The Japan Society for Aeronautical and Space Sciences and ISTS, vol. 20, no. ists31, pp. 1-8, 2017.

[14] J. Yang, C. Huang, Y. Wang, and K. Li, "Design and testing of a novel passive isolator for a space optical payload," Journal of Harbin Institute of Technology, vol. 25, no. 2, pp. 85-96, 2018.
[15] D. Robinson and S. Tonn, "Mechanical Aspects of the Thermal Infrared System (TIRS) on Landsat 8," in 2015 IEEE Aerospace Conference, pp. 1-10, Big Sky, MT, USA, 2015.

[16] A. Burkic and R. Little, "Integrated Cryocooler assemblies for miniature satellite applications," in International Cryocooler Conference, pp. 567-573, Boulder, CO, USA, 2016.

[17] S. C. Kwon, M. S. Jo, D. H. Ko, and H. U. Oh, "Viscoelastic multilayered blade-type passive vibration isolation system for a Spaceborne cryogenic cooler," Cryogenics, vol. 105, p. 102982, 2020.

[18] H. U. Oh, K. J. Lee, and M. S. Jo, "A passive launch and on-orbit vibration isolation system for the spaceborne cryocooler," Aerospace Science and Technology, vol. 28, no. 1, pp. 324-331, 2013.

[19] https://directory.eoportal.org/web/eoportal/satellite-missions/ k/kompsat-3a.

[20] https://www.aquariusplastics.co.uk/.

[21] H.-U. Oh, S. Shin, and C.-W. Baek, "Thermal control of Spaceborne image sensor using heat pipe cooling system," Aerospace Science and Technology, vol. 29, no. 1, pp. 394-402, 2013.

[22] D. J. Inman, Engineering Vibration, Pearson, 4th edition, 2015. 